\title{
Cerebrospinal fluid-stem cell interactions may pave the path for cell-based therapy in neurological diseases
}

\author{
Chao Ren ${ }^{1 \dagger}$, Peiyuan Yinn ${ }^{2 \dagger}$, Neng Ren ${ }^{3 \dagger}$, Zhe Wang ${ }^{4}$, Jiahui Wang ${ }^{5}$, Caiyi Zhang ${ }^{6}$, Wei Ge ${ }^{6 *}$, Deqin Geng ${ }^{6 *}$ \\ and Xiaotong Wang ${ }^{1 *}$
}

\begin{abstract}
Recent studies have suggested that the regulation of endogenous neural stem cells (NSCs) or transplanting of exogenous nerve cells are the newest and most promising methods for the treatment of dementia and other neurological diseases. The special location and limited number of endogenous NSCs, however, restrict their clinical application. The success in directional differentiation of exogenous stem cells from other tissue sources into neural cells has provided a novel source for NSCs. Study on the relative mechanisms is still at the preliminary stage. Currently the induction methods include: 1) cell growth factor induction; 2) chemical induction; 3) combined growth factor-chemical induction; or 4) other induction methods such as traumatic brain tissue homogenate, gene transfection, traditional Chinese medicine, and coculture induction. Cerebrospinal fluid (CSF), as a natural medium under physiological conditions, contains a variety of progrowth peptide factors that can promote the proliferation and differentiation of mesenchymal stromal cells (MSCs) into neural cells through the corresponding receptors on the cell surface. This suggests that CSF can not only nourish the nerve cells, but also become an effective and suitable inducer to increase the yield of NSCs. However, some other studies believed that CSF contained certain inhibitory components against the differentiation of primary stem cells into mature neural cells. Based on the above background, here we review the relative literature on the influence of the CSF on stem cells in order to provide a more comprehensive reference for the wide clinical application of NSCs in the future.
\end{abstract}

Keywords: Cerebrospinal fluid, Stem cells, Induced differentiation, Neural stem cells, Stem cell transplantation therapy

\section{Background}

The clinical treatment of neurological diseases, especially degenerative diseases of the nervous system, has always proved very difficult. Only by symptomatic treatment can we delay the progression of the disease as much as possible; however, the treatment efficacy is generally dissatisfactory, not to mention the hope of a complete cure. The reason for this is that once the nerve cells are damaged and degenerated they cannot self-repair. Can neurological function loss caused by neurological diseases be improved or even

\footnotetext{
*Correspondence: gw1003@163.com; gengdeqin@126.com;

xiaotong67@163.com

${ }^{\dagger}$ Equal contributors

${ }^{6}$ Department of Neurology, Affiliated Hospital of Xuzhou Medical University, Xuzhou 221004, China

'Department of Neurology, Affiliated Yantai Yuhuangding Hospital of Qingdao University, Yantai 264000, China

Full list of author information is available at the end of the article
}

cured by nerve regeneration or functional replacement by neighboring nerves? The answer is positive. Research over recent years has found that the nerves of patients with neurological diseases have certain self-repair potential after nervous system injury [1], and proliferative neural stem cells (NSCs) can still be found in adult nervous tissues. Therefore, the latest and most promising method to treat neurological diseases is by artificial intervention and regulation of endogenous NSCs, which can promote their proliferation and differentiation, or by nerve cell transplantation to promote the repair of central nervous system injury. Because of the special location and limited number of endogenous NSCs, their clinical application has been restricted. Although embryonic (including umbilical cord) stem cells are good source libraries of exogenous NSCs and these have made great progress in animal models, their clinical applications have been strictly restricted due to 
reproductive ethical problems [2]. Former president of the United States, Mr. Bush, issued an injunction in 2001 to prohibit the federal government from funding human embryonic stem cell research. The recent trend of induced pluripotent stem cell (iPSC) research no longer has this reproductive ethics problem. However, since it introduces some transcription factors into animal or human somatic cells through gene transfection which leads to the direct reconstruction of somatic cells into embryonic stem celllike pluripotent cells, the risk of carcinogenesis is higher than in normal cells. In addition, it is technically demanding and complicated in operation, which has restricted its clinical application. The discovery of the pluripotency of bone marrow-derived mesenchymal stromal cells (BMMSCs) and the success of directional differentiation of nerve cells has provided a new source of NSCs [3]. The study on the mechanism of BM-MSCs differentiating into neural cells is still at a preliminary stage. At present, the main induction methods include: 1) cell growth factor induction by epidermal growth factor (EGF), basic fibroblast growth factor (bFGF), nerve growth factor (NGF), and so forth [4]; 2) chemical induction by $\beta$-mercaptoethanol (B-ME), dimethyl sulfoxide (DMSO), butylated hydroxyanisole (BHA), and so forth [5]; 3) growth factor and chemical combined induction (Woodbury et al. [6] used B-ME, DMSO, and bFGF combined induction while Kögler et al. [7] utilized NGF, bFGF, DB-cAMP, isobutylmethyl xanthine, and RA for combined induction of BM-MSCs into nerve cells in vitro); and 4) other methods such as traumatic brain tissue homogenate [8], gene transfection [9], traditional Chinese medicine (Baicalin, Salvia miltiorrhiza, and so forth) [10], coculture, and conditioned growth medium close to the physiological state. Cytokines are widely used inducers due to their extensive function in neural nutrition, antifree radicals, reducing calcium overload, and inhibiting the expression of nitric oxide synthase. Among them, EGF and bFGF are most representative as they are not only strong polypeptide factors for promoting cell growth, but also important mitogens which promote the proliferation and differentiation of BM-MSCs through corresponding receptors on the cell surface [11]. However, these are all exogenous substances that more or less impose certain risks. It has been one of the goals of stem cell researchers to find inducers that are close to the microenvironment of the human body, preferably the human body's own secretion. Cerebrospinal fluid (CSF), as a natural medium at the physiological state, is the best candidate [12]. CSF is mainly secreted by the lateral ventricle choroid plexus epithelial cells. It is a colorless and transparent liquid that contains a variety of electrolytes, proteins, sugars, and various growth factors such as the brain-derived and gliocyte-derived neurotrophic factors [13]. These factors in CSF can promote the proliferation and differentiation of MSCs into nerve cells through the corresponding receptors on the cell surface, suggesting that the differentiation of MSCs is tissue-specific and that the tissue microenvironment can induce its directional differentiation [14]. This indicates that CSF can not only nourish the nerve cells, but can also act as an effective and suitable inducer thus providing a new source of NSCs [15]. On the other hand, some studies have suggested that the inhibitory components in CSF might suppress the differentiation of related primary stem cells into mature nerve cells [16]. Based on the above information, here we review the reported effects of CSF on stem cells in the worldwide literature in order to provide references for the future clinical application of NSCs.

\section{Effects of CSF on MSCs}

Yan and colleagues reported that BM-MSCs displayed neuronal morphology 4-5 days after autologous CSF induction, differentiated into neurons, astrocytes, and oligodendrocytes, and exhibited corresponding characteristic structure and biological features [17]. Our group had similar observations in our previous studies, and the same effect was also observed in umbilical cord blood mesenchymal stromal cells (UCB-MSCs) [3, 12, 18-25]. Farivar et al. [26] also confirmed that CSF could induce the differentiation of UCB-MSCs into neuronal cells, although the concentration of CSF used for the induction and the time needed for differentiation was slightly different. These studies suggested that MSCs can grow in CSF and maintain their potential of differentiation into neural cells. Shen et al. [27] also showed that the growth characteristics of MSC in CSF and in general medium were similar. As we have shown, the number of various hemocytes in the suspension decreases during the rapid growth of MSCs suggesting suppressed proliferation or differentiation of hematopoietic stem cells and suggesting that CSF favors the growth of MSCs over hematopoietic stem cells which contributes to the isolation and culture of MSCs from bone marrow or umbilical cord blood. However, attention should be paid to the protocols for CSF culture and induction because of the potential of MSCs to differentiate into different tissue cells in different culture media. Therefore, different culture media formulae are needed based on the purpose of the culture.

The mechanism of CSF-induced differentiation of MSCs into nerve cells is rarely discussed, but it is theoretically proposed that the microenvironment within the brain or the spinal cord provides the necessary conditions for the induced directional differentiation of MSCs, although the specific functioning elements are still unknown. Recently Zhu et al. [28] identified that CSF regulated the proliferation and migration of stem cells through insulin-like growth factor 1 (IGF-1), while Glage et al. [29] suggested that glucagon-like peptide 1 (GLP-1) might be an important regulator for this process. Some researchers [30-33] believe that it is the result of the direct interaction between the choroid plexus cells and MSCs in CSF, or the 
fusion of these two types of cells. Other scholars [34, 35] proposed that the microecological signals of choroid plexus cells might be an important factor regulating the differentiation and migration of stem cells, and that PRDM16 might be an important regulator in this signaling pathway [35]. In addition, a study [36] found that the CSF of amyotrophic lateral sclerosis patients could also promote MSCs to differentiate into neuron-like cells. Currently, the study of the influence of the CSF on MSCs is not limited to induction experiments-there have been reports on the use of nerve cells obtained from induced MSCs in clinical treatment and which have shown certain effects $[3,18,20,25,37]$.

\section{Effects of CSF on embryonic stem cells (ESCs)}

Bian et al. [38] induced the differentiation of human embryonic stem cells (hESCs) into neuron-like cells (such as neurons, astrocytes, and oligodendrocytes) using healthy human CSF, but the proportion of each cell type was different. The proportion of glial cells was higher, likely because CSF contains more factors that preferably induce the differentiation of stem cells into glial cells. Chen et al. [39] used bloody CSF to induce ESCs and obtained a higher proportion of glial cells which might be related to the increase of stimulating factors for glial cell proliferation in CSF after traumatic brain injury. During the study of migration and differentiation of human fetal brain NSCs in developmental CSF, Yin et al. [40] found that in the embryo there were large differences in the information substances secreted by ESCs at different developmental stages, which in turn affected the components of the CSF since the blood-brain barrier was not yet formed and the brain was therefore in an open state. Furthermore, the different active constituents in the CSF could also affect the development and differentiation of ESCs. This further confirmed that the production of glial cells may be closely related to the specifics of the CSF environment.

Unlike the above research on obtaining glial cells from induced ESCs, Xu et al. [41] used certain concentrations of ascorbic acid to induce the differentiation of ESCs, and then adult CSF was used instead to induce the directional differentiation of embryonic brain stem cells into dopaminergic neurons. Zappaterra et al. [42] identified the CSF fluid pressure to be an important contributing factor to the differentiation and migration of ESCs, while Martin et al. [43] proposed FGF2 to be an important factor in CSF-induced ESC differentiation. Through genetic analysis, factors in CSF have been confirmed to greatly influence the early embryonic development process, especially the differentiation and formation of nerve cells [44]. Kiiski et al. [45] found that the CSF from healthy people promoted the differentiation of hESCs into neurocytes and the formation of a neural network with spontaneous activity. However, another study suggested that adult CSF did not support neurogenesis of ESCs [46]. There have been other reports that CSF suppressed the differentiation of ESCs into neurons but promoted their differentiation into glial cells [47]. The inconsistency of these results might be due to the different sources of ESCs and CSF used in the studies.

\section{Effect of CSF on NSCs}

Li [48] found that after spinal cord injury the changes in the CSF components affected the proliferation and differentiation of endogenous NSCs in the spinal cord. Another comparison study [49] found that: 1) NSCs can survive, proliferate, and differentiate in the bloody CSF and hydrocephalus clear CSF; 2) the adherent differentiation of NSCs in the traumatic bloody CSF was faster than that in the hydrocephalus clear CSF, and the proportion of adherent differentiation was also higher; and 3) there was difference in the cell types of NSC differentiation in traumatic bloody CSF and hydrocephalus clear CSF. NSCs were prone to differentiate into glial cells in traumatic bloody CSF and into neurons in hydrocephalus clear CSF. Teng et al. [50] discovered that the CSF of ischemic rats could promote the survival of NSCs in vitro and induced the differentiation of NSCs into neurons and astrocytes. Nozaki et al. [51] studied the CSF of patients with subarachnoid hemorrhage and identified bloody CSF to be an effective stimulant to activate and promote the proliferation and differentiation of endogenous NSCs. Haines et al. [52] reported that the CSF of multiple sclerosis patients induced transcriptional changes in oligodendrocyte progenitor cells of the NSCs. The above research suggested that CSF under morbid conditions might be an important factor to initiate patient's self-endogenous nerve repair [53, 54] but that during the repair there was a difference in the differentiation direction of NSCs [55]. In most cases NSCs mainly differentiate into glial cells [15] and less frequently predominantly into neuron-like cells [56]. Thus a current research hotspot in treating neurological diseases with induced endogenous stem cells is how to obtain the desired cells for clinical treatment, currently drug-containing CSF, and especially traditional Chinese medicine CSF pharmacology [57]. Our research group is currently exploring the treatment of dementia using the transplantation of EGb761 CSF pharmacology-mediated circulating stem cells.

\section{Conclusions: Problems and prospects}

Currently, a growing number of studies (Table 1) have suggested that the CSF-stem cell interaction is a potential for the treatment of neurological diseases [16]. This is because CSF not only provides the microenvironment for stem cell growth [13] and acts as the regulator for 


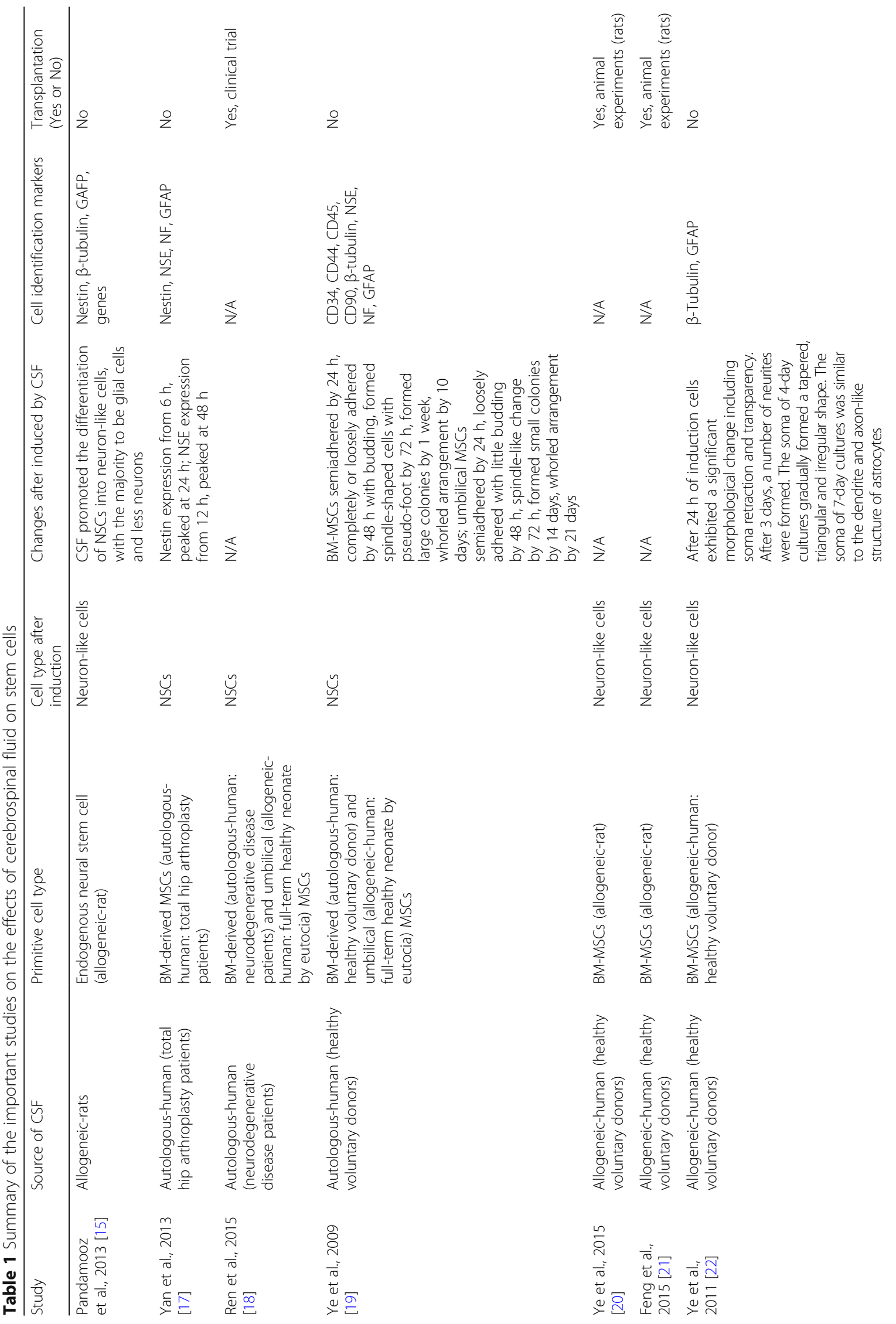




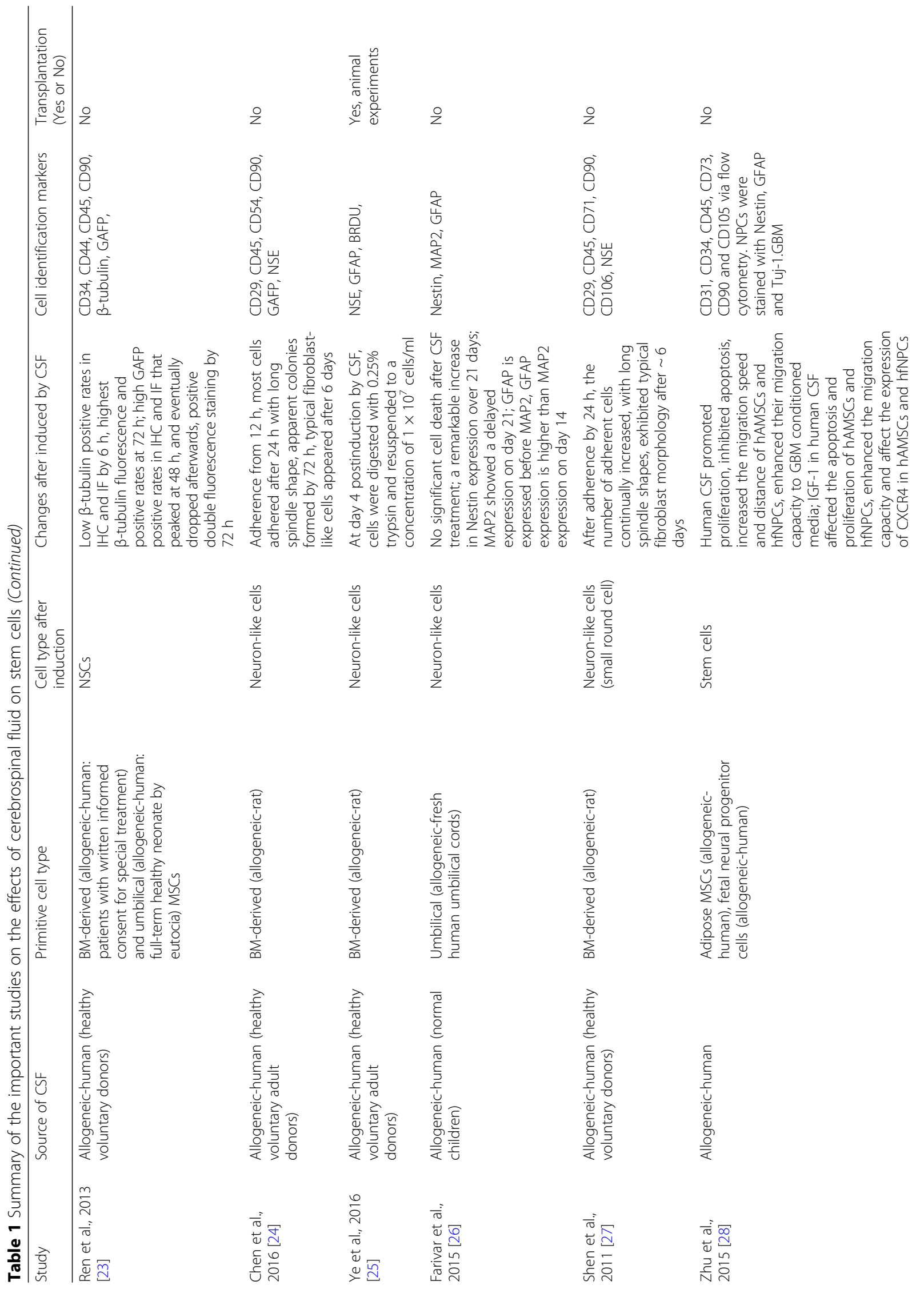




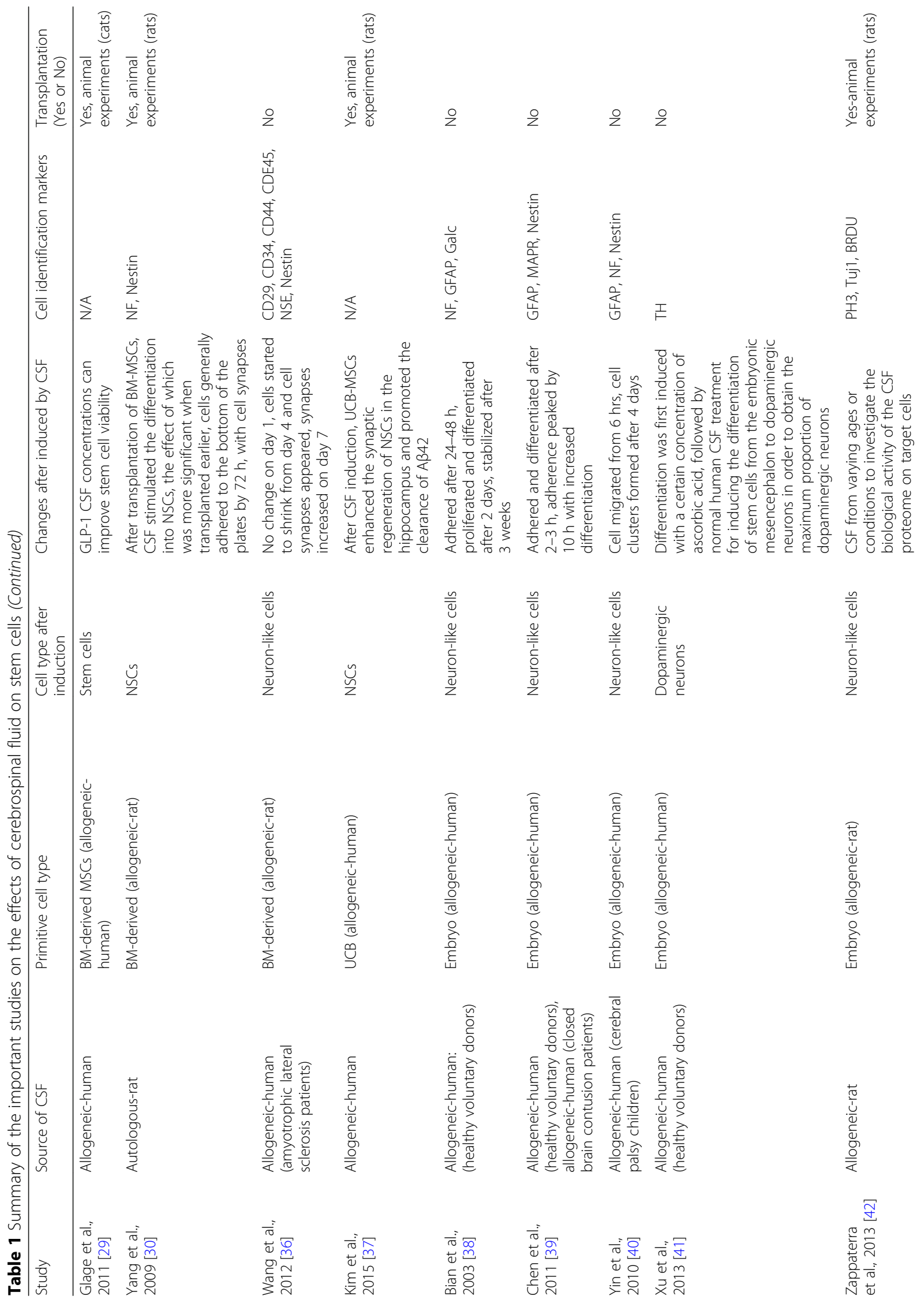




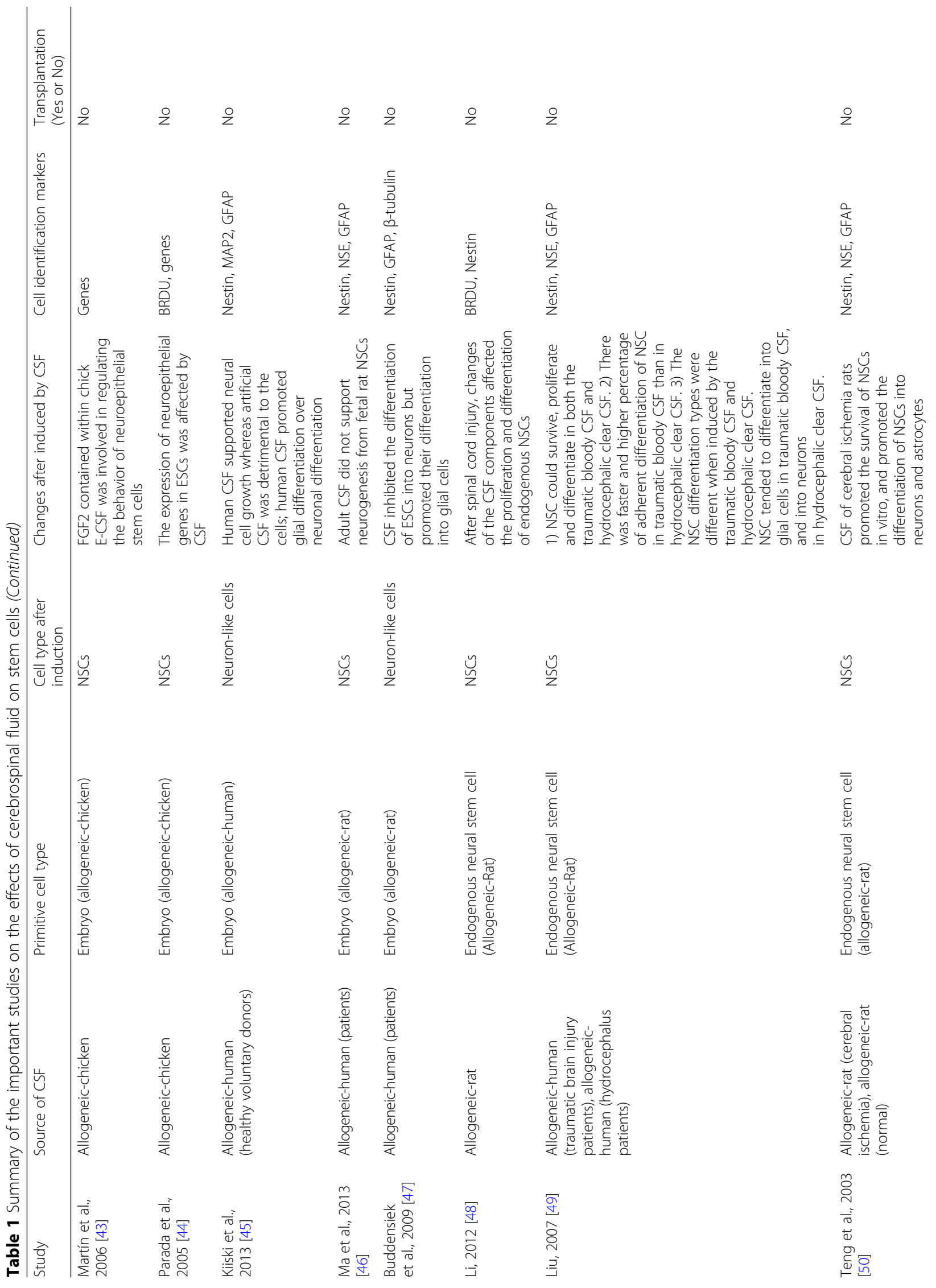




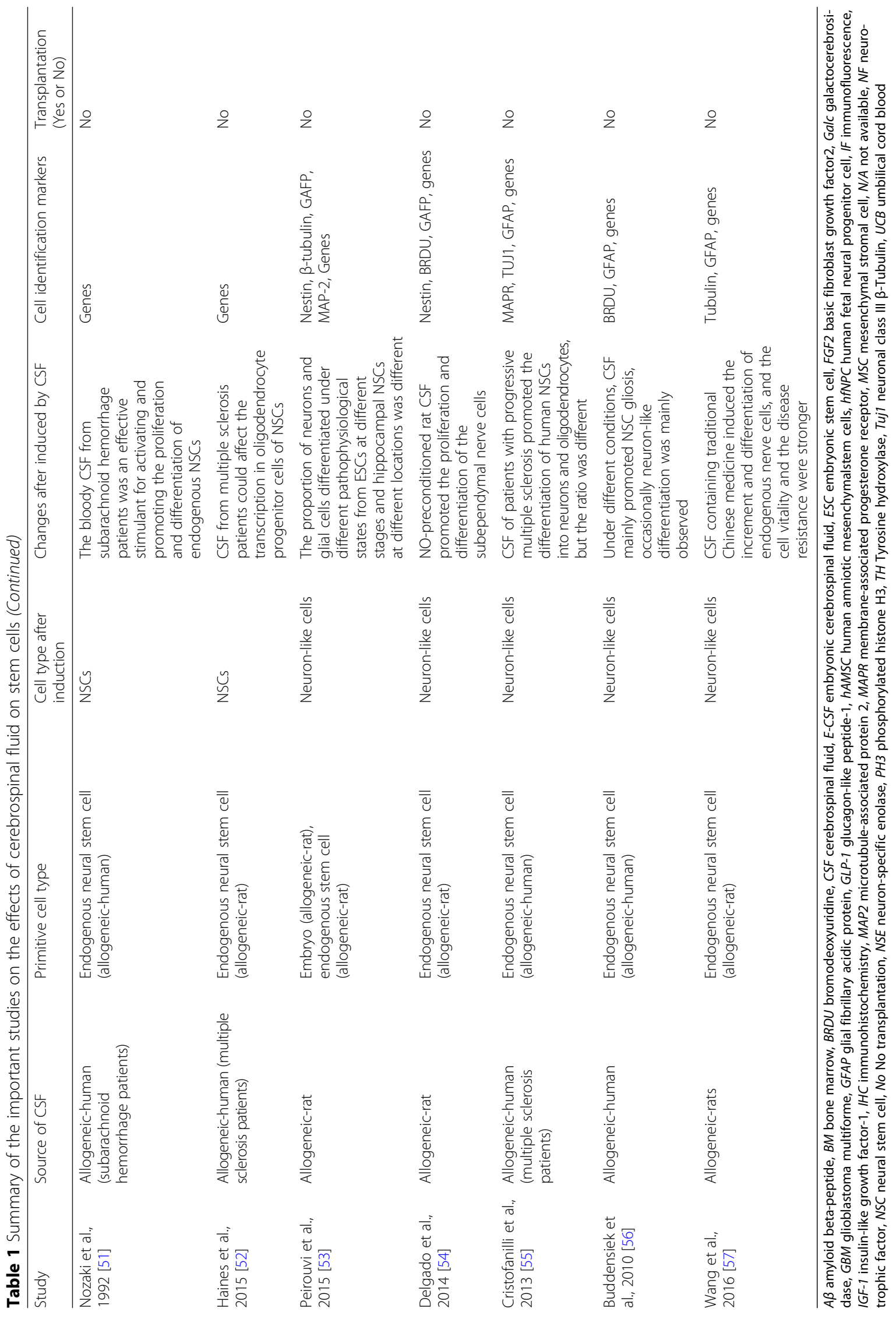


stem cell differentiation [58], but it also conducts cell signals to stimulate self-healing [59]. However, in the absence of unified and/or preferential stem cell culture and identification methods, and specifications and/or guidelines for stem cell transplantation approaches, conditions and time windows, there will inevitably be some negative reports and exaggerated propaganda, such as the controversial "stem cell tourism" [60]. What should we do in the face of this embarrassment? Sometimes it might be "better to leap before looking" [61]. As Nobel Prize winner Martin Evans said during his interview with Life Times, the key point of stem cell research is to apply experimental results to clinical practice. Based on previous experiences $[3,18]$, we propose that the synchronous treatment and acquisition of CSF through CSF circulating transplantation broke the boundary between stem cell induction and treatment, and circumvented the limitation of transplantation routes including stereotactic injection, operation injection, and intravenous infusion. It is an effective and clinically feasible individualized stem cell transplantation treatment mode. However, this is based on only small-scale clinical research. Further multicenter and large-scale randomized control trials are needed to solve the following major questions: 1 ) What is the specific substance(s) in CSF that induces the differentiation of stem cells? 2) What is the proportion of target cells derived from CSF-induced differentiation, and how to increase this proportion? 3) Why are there were differences in obtaining functional stem cells from different sources of mesenchymal stromal cells [62, 63]? 4) How do we prevent stem cells senescence and maintain multiple attributes [64-66]? 5) How many stem cells should be used for transplantation? 6) How do we control the proliferation, differentiation, migration, and tumorigenesis of the stem cells after implantation into the nervous system? 7) Why are there are no standard guidelines for the indications, routes, and timing of transplantation, or the evaluation criteria of treatment results? In this regard, we agree with the opinion of responsible professionals and experts that basic research and applied basic research of CSF-induced stem cells should be encouraged, while standardized clinical research of a scientific nature can be performed in those hospitals with appropriate facilities. Without confirmed results from relevant research, CSF-induced stem cells are currently not recommended for large-scale clinical application, and for-profit marketing and exaggerated commercialized propaganda should be prohibited.

\section{Acknowledgements}

Not applicable.

\section{Funding}

This study was funded by National Natural Science Foundation of China (grant number 81501185), Shandong Provincial Key Research \& Development Project (grant number 2017GSF218043), and the open projects of Jiangsu
Key Laboratory of New Drug Research and Clinical Pharmacy (grant number KF-XY201407).

\section{Availability of data and materials}

Data sharing is not applicable to this article as no datasets were generated or analyzed during the current study.

\section{Authors' contributions}

CR found the references and drafted the manuscript, PY and NR read the literature. ZW summarized the information. JW helped to draft the manuscript. CZ designed the literature retrieval strategy. XW modified the manuscript. WG and DG guided the above work. All authors read and approved the final manuscript.

Ethics approval and consent to participate

Not applicable.

Consent for publication

Not applicable.

\section{Competing interests}

The authors declare that they have no competing interests.

\section{Publisher's Note}

Springer Nature remains neutral with regard to jurisdictional claims in published maps and institutional affiliations.

\section{Author details}

${ }^{1}$ Department of Neurology, Affiliated Yantai Yuhuangding Hospital of Qingdao University, Yantai 264000, China. ${ }^{2}$ Department of Blood Supply, Yantai Center Blood Station, Yantai 264000, China. ${ }^{3}$ Department of Inervention Therapy, Affiliated Hospital of Xuzhou Medical University, Xuzhou 221004, China. ${ }^{4}$ Department of Clinical Laboratory, Affiliated Yantai Yuhuangding Hospital of Qingdao University, Yantai 264000, China. ${ }^{5}$ Department of Central Laboratory, Affiliated Yantai Yuhuangding Hospital of Qingdao University, Yantai 264000, China. ${ }^{6}$ Department of Neurology, Affiliated Hospital of Xuzhou Medical University, Xuzhou 221004, China.

Published online: 09 March 2018

\section{References}

1. Kuhn HG, Svendsen CN. Origins, functions, and potential of adult NSCs. BioEssays. 1999;21(8):625-30.

2. Vogel G. Europe: dismay, confusion greet human stem cell patent ban. Science. 2011;334(6055):441-2.

3. Ren C, Geng RL, Ge W, et al. An observational study of autologous bone marrow-derived stem cells transplantation in seven patients with nervous system diseases: a 2-year follow-up. Cell Biochem Biophys. 2014;69(1):179-87.

4. Low CB, Liou YC, Tang BL. Neural differentiation and potential use of stem cells from the human umbilical cord for central nervous system transplantation therapy. J Neurosci Res. 2008;86(8):1670-9.

5. Kang XQ, Zang WJ, Bao L, et al. Differentiating characterization of human umbilical cord blood-derived mesenchymal stem cells in vitro. Cell Biol Int. 2006;30(7):569-75

6. Woodbury D, Schwarz EJ, Prockop DJ, et al. Adult rat and human bone marrow stromal cells differentiate into neurons. J Neurosci Res. 2000;61(4):364-70.

7. Kögler G, Sensken S, Airey JA, et al. A new human somatic stem cell from placental cord blood with intrinsic pluripotent differentiation potential. J Exp Med. 2004;200(2):123-35

8. Yong-zhou S, Hui-xian C, Zhe L, et al. Effects of brain homogenate on the differentiation of rat bone mesenchymal stem cells into neuron-like cells following traumatic brain injury. J Clin Rehabil Tissue Eng Res. 2008;12(3):461-4.

9. Lim JY, Park SI, Oh JH, et al. Brain-derived neurotrophic factor stimulates the neural differentiation of human umbilical cord blood-derived mesenchymal stem cells and survival of differentiated cells through MAPK/ERK and PI3K Akt-dependent signaling pathways. J Neumsci Res. 2008:86(10):2168-78.

10. Jia $Y$, Yang $Y$, Zhou $Y$, et al. Differentiation of rat bone marrow stromal cells into neuron induced by baicalin. Zhonghua Yi Xue Za Zhi. 2002:82(19): 1337-41. [In Chinese] 
11. Tureyen $K$, Vemuganti $R$, Bowen KK, et al. EGF and FGF-2 in fusion increases post-ischemic neural progenitor cell proliferation in the adult rat brain. Neurosurgery. 2005;57(6):1254-63.

12. Ge W, Ren C, Duan $X$, et al. Differentiation of mesenchymal stem cells into NSCs using cerebrospinal fluid. Cell Biochem Biophys. 2015;71(1):449-55.

13. Illes S. More than a drainage fluid: the role of CSF in signaling in the brain and other effects on brain tissue. Handb Clin Neurol. 2017:146:33-46.

14. Rivera FJ, Sierralta WD, Minguell JJ, et al. Adult hippocampus derived soluble factors induce a neuronal-like phenotype in mesenchymal stem cells. Neurosci Lett. 2006:406(1-2):49-54.

15. Pandamooz S, Naji M, Alinezhad F, et al. The influence of cerebrospinal fluid on epidermal neural crest stem cells may pave the path for cell-based therapy. Stem Cell Res Ther. 2013;4(4):84.

16. Imitola J, Durvasula S. The cerebrospinal fluid-stem cells interactions as target for regenerative therapy in neurological diseases. Stem Cells Dev. 2015:24(2):145-6.

17. Yan L, Li X, Sun Y, et al. Homocerebrospinal fluid induces bone mesenchymal stem cells to differentiate into neural stem cells. Jiangsu Med J. 2013;39(6):645-7. [In Chinese]

18. Ren C, Zhang CY, Ding HM, et al. A study on the treatment of neurodegenerative diseases with mesenchymal stem cells induced by cerebrospinal fluid. Chin J Emerg Rescue Disaster Med. 2015;10(7):608-11. [In Chinese]

19. Ye Y, Wan MR, Dai RF, et al. Study on cerebrospinal fluid differential of mesenchymal stem cells into neuron in vitro. Int J Anesth Resus. 2009;30(5): 394-8. [In Chinese]

20. Ye Y, Xie X, Liu X, et al. A safety study of the transplantation of CSF-induced bone marrow-derived neuron-like cells. Chin J Emerg Rescue Disaster Med. 2015:10(6):521-5. [In Chinese]

21. Feng TT, Ye Y, Xu T. Effects of CSF-induced bone marrow-derived neural-like cells on secretion of neurotrophic factor in rats with spinal cord injury. Chin J Emerg Rescue Disaster Med. 2015;10(7):612-5. [In Chinese]

22. Ye $Y$, Zeng $Y M$, Wan MR, et al. Induction of human bone marrow mesenchymal stem cells differentiation into neural-like cells using cerebrospinal fluid. Cell Biochem Biophys. 2011;59(3):179-84.

23. Ren C, Liu X, Wan M, et al. A comparative study on inducing nonhomologous mesenchymal stem cells to differentiate into NSCs using nonhomologous cerebrospinal fluid. J Biomed Eng. 2013;30(6):1290-7.

24. Chen J, Xie X, Peng Y, et al. Study on the directed differentiation of human cerebrospinal fluid-induced bone marrow mesenchymal stem cells into neuron like cells. Acta Academiae Medicinae Xuzhou. 2016;36(4):254-7. [In Chinese]

25. Ye $Y$, Peng $Y$, Hu S, et al. In vitro differentiation of bone marrow mesenchymal stem cells into neuron-like cells by cerebrospinal fluid improves motor function of middle cerebral artery occlusion rats. Front Neurol. 2016;7:183

26. Farivar S, Mohamadzade $Z$, Shiari $R$, et al. Neural differentiation of human umbilical cord mesenchymal stem cells by cerebrospinal fluid. Iran J Child Neurol. 2015;9(1):87-93.

27. Shen $Y X$, Wang $P$, Shi E. Influence of cerebrospinal fluid on in vitro culture of bone marrow mesenchymal stem cells. J Clin Rehabil Tissue Eng Res. 2011;15(36):6802-6. [In Chinese]

28. Zhu M, Feng $Y$, Dangelmajer $S$, et al. Human cerebrospinal fluid regulates proliferation and migration of stem cells through insulin-like growth factor 1. Stem Cells Dev. 2015:24(2):160-71.

29. Glage S, Klinge PM, Miller MC, et al. Therapeutic concentrations of glucagon-like peptide-1 in cerebrospinal fluid following cell-based delivery into the cerebral ventricles of cats. Fluids Barriers CNS. 2011;8(1):1-7.

30. Yang HY, Gu R, Wang WJ, et al. Research on the effect of BMSCs-CSF on the differentiation of neurosphere cells. Chin J Lab Diagn. 2009;13(3):300-2. [ln Chinese]

31. Wu S, Suzuki $Y$, Ejiri $Y$, et al. Bone marrow stromal cells enhance differentiation of cocultured neurosphere cells and promote regeneration of injured spinal cord. J Neurosci Res. 2003;72(3):343-51.

32. Roballo KC, Gonçalves NJ, Pieri NC, et al. Regulation of NSCs by choroid plexus cells population. Neurosci Lett. 2016;626:35-41.

33. Moore SA. The spinal ependymal layer in health and disease. Vet Pathol. 2016;53(4):746-53.

34. Silva-Vargas V, Maldonado-Soto A, Mizrak D, et al. Age-dependent niche signals from the choroid plexus regulate adult NSCs. Cell Stem Cell. 2016;19(5):643-52.
35. Kazanis I, Ffrench-Constant C. The number of stem cells in the subependymal zone of the adult rodent brain is correlated with the number of ependymal cells and not with the volume of the niche. Stem Cells Dev. 2012;21(7):1090-6.

36. Wang $Y$, Yang $C$, Sun $Y$, et al. The effect of the cerebrospinal fluid of amyotrophic lateral sclerosis patients on the proliferation and differentiation of bone marrow mesenchymal stem cells. Stroke Nerv Dis. 2012;19(6):32831. [In Chinese]

37. Kim DH, Lee D, Chang EH, et al. GDF-15 secreted from human umbilical cord blood mesenchymal stem cells delivered through the cerebrospinal fluid promotes hippocampal neurogenesis and synaptic activity in an Alzheimer's disease model. Stem Cells Dev. 2015;24(20):2378-90.

38. Bian L, Hui GZ, Lu H, et al. Experimental study on the differentiation of neural stem cells derived from human embryo from normal adult cerebrospinal fluid. J Clin Med Prac. 2003;7(3):202-4. [In Chinese]

39. Chen $X$, Yin $G$, Zheng $A$, et al. Effect of hemorrhagic cerebrospinal fluid on human embryonic neural stem cells. Med J Wuhan Uni. 2011;32(4):480-3. [In Chinese]

40. Yin GC, Chen XS, Zheng AF, et al. Migration and differentiation of neural stem cells derived from a human fetus brain in developmental cerebrospinal fluid. J Clin Rehabl Tissue Eng. 2010;14(1):24-7. [In Chinese]

41. Xu J, Fang WF, Zhu AH. Differentiation of neural stem cells derived from human embryonic mesencephalon into dopaminergic neurons in vitro. China, CN103045538A. 2013-04-17. [In Chinese].

42. Zappaterra MW, Lamantia AS, Walsh CA, et al. Isolation of cerebrospinal fluid from rodent embryos for use with dissected cerebral cortical explants. J Vis Exp. 2013;73:e50333.

43. Martín C, Bueno D, Alonso Ml, et al. FGF2 plays a key role in embryonic cerebrospinal fluid trophic properties over chick embryo neuroepithelia stem cells. Dev Biol. 2006;297(2):402-16.

44. Parada C, Martín C, Alonso Ml, et al. Embryonic cerebrospinal fluid collaborates with the isthmic organizer to regulate mesencephalic gene expression. J Neurosci Res. 2005:82(3):333-45.

45. Kiiski H, Äänismaa R, Tenhunen J, et al. Healthy human CSF promotes glial differentiation of hESC-derived neural cells while retaining spontaneous activity in existing neuronal networks. Biology Open. 2013;2(6):605-12.

46. Ma Y, Liu M, He B. Adult cerebrospinal fluid does not support neurogenesis from fetal rat NSCs. Neurol Sci. 2013;34(5):735-9.

47. Buddensiek J, Dressel A, Kowalski M, et al. Adult cerebrospinal fluid inhibits neurogenesis but facilitates gliogenesis from fetal rat NSCs. J Neurosci Res. 2009;87(14):3054-66.

48. Li Q. Effect of cerebrospinal fluid on the proliferation and differentiation of endogenous neural stem cells. China: Tianjin Med Uni; 2012. [In Chinese]

49. Liu GP. Effect of cerebrospinal fluid on the proliferation and differentiation of neural stem cells. China: Zhongnan Uni; 2007. [In Chinese]

50. Teng H, Gao DY, Zhu XF. The effect of cerebrospinal fluid on the survival and differentiation of neural stem cells in rats with cerebral ischemia. Heilongjiang Med Pharm. 2003;26(5):10-2. [In Chinese]

51. Nozaki K, Boccalini P, Moskowitz MA. Expression of c-fos-like immunoreactivity in brainstem after meningeal irritation by blood in the subarachnoid space. Neuroscience. 1992;49(3):669-80.

52. Haines JD, Vidaurre OG, Zhang F, et al. Multiple sclerosis patient-derived CSF induces transcriptional changes in proliferating oligodendrocyte progenitors. Mult Scler. 2015;21(13):1655-69.

53. Peirouvi T, Yekani F, Azarnia M, et al. High neuronal/astroglial differentiation plasticity of adult rat hippocampal neural stem/progenitor cells in response to the effects of embryonic and adult cerebrospinal fluids. Iran J Vet Res. 2015;16(1):83-9.

54. Delgado AC, Ferrón SR, Vicente D, et al. Endothelial NT-3 delivered by vasculature and CSF promotes quiescence of subependymal NSCs through nitric oxide induction. Neuron. 2014;83(3):572-85.

55. Cristofanilli M, Cymring B, Lu A, et al. Cerebrospinal fluid derived from progressive multiple sclerosis patients promotes neuronal and oligodendroglial differentiation of human neural precursor cells in vitro. Neuroscience. 2013;250(8):614-21.

56. Buddensiek J, Dressel A, Kowalski M, et al. Cerebrospinal fluid promotes survival and astroglial differentiation of adult human neural progenitor cells but inhibits proliferation and neuronal differentiation. BMC Neurosci. 2010;11(1):48.

57. Wang K, Zhang LL, Song WS, et al. Effects of cerebrospinal fluid containing Yishen Huazhuo Decoction on proliferation and differentiation of neural stem cells via JNK2/STAT3 signaling pathway. Chin J Trad Chin Med. 2016; 31(5):1879-82. [In Chinese] 
58. Lehtinen MK, Zappaterra MW, Chen X, et al. The cerebrospinal fluid provides a proliferative niche for neural progenitor cells. Neuron. 2011;69(5):893-905.

59. Zappaterra MW, Lehtinen MK. The cerebrospinal fluid: regulator of neurogenesis, behavior, and beyond. Cell Mol Life Sci. 2012;69(17):2863-78.

60. Einsiedel EF, Adamson H. Stem cell tourism and future stem cell tourists: policy and ethical implications. Dev World Bioeth. 2012;12(1):35-44.

61. Freedman MS, Uccelli A. Neurorepair with mesenchymal stem cells: hope or hype? Lancet Neurol. 2012;11(2):123-5.

62. Squillaro T, Peluso G, Galderisi U. Clinical trials with mesenchymal stem cells: an update. Cell Transplant. 2016;25(5):829-48.

63. Okolicsanyi RK, Camilleri ET, Oikari LE, et al. Human mesenchymal stem cells retain multilineage differentiation capacity including neural marker expression after extended in vitro expansion. PLoS One. 2015;10(9): e0137255.

64. Galipeau J. The mesenchymal stromal cells dilemma—does a negative phase III trial of random donor mesenchymal stromal cells in steroidresistant graft-versus-host disease represent a death knell or a bump in the road? Cytotherapy. 2013;15(1):2-8.

65. Stefania C, Nicola A, Tiziana S, et al. Changes in autophagy, proteasome activity and metabolism to determine a specific signature for acute and chronic senescent mesenchymal stromal cells. Oncotarget. 2015;6(37): 39457-68.

66. Alessio N, Del GS, Capasso S, et al. Low dose radiation induced senescence of human mesenchymal stromal cells and impaired the autophagy process. Oncotarget. 2014;6(10):8155-66. 